\title{
PRIVATIZACIÓN, COMPETENCIA POR DEPÓSITOS Y DESEMPEÑO BANCARIOS*
}

\author{
PRIVATIZATION, COMPETITION FOR DEPOSITS AND \\ PERFORMANCE IN BANKING
}

Antonio RuIZ-PorRas**

\begin{abstract}
Resumen
En este artículo desarrollamos un marco microeconómico para estudiar las relaciones entre la privatización, la competencia por depósitos y el desempeño bancarios. Particularmente analizamos la privatización bancaria cuando se permiten estrategias competitivas de los tipos Cournot y Stackelberg. Nuestros hallazgos muestran que ciertas condiciones son necesarias para justificarla bajo los siguientes criterios: (i) eficiencia, (ii) poder de mercadolestabilidad financiera y (iii) disponibilidad de consumo para los depositantes. También muestran que la privatización es relativamente sencilla de justificar cuando se permiten relaciones líder-seguidor en el sistema bancario. Incluso, los ingresos gubernamentales, por privatizar, son más altos cuando existen estas relaciones.
\end{abstract}

Palabras clave: Banca, privatización, competencia, desempeño, depósitos.

\begin{abstract}
In this article we develop a microeconomic framework to study the relationships among privatization, competition for deposits and performance in banking. Particularly, we analyze banking privatization when competitive strategies of the Cournot and Stackelberg types are allowed. Our findings show that some conditions are necessary to justify it under the following criteria: (i) efficiency, (ii) market power/financial stability and (iii) consumption availability for depositors. They also show that privatizations are relatively easy to justify when
\end{abstract}

* El autor agradece los valiosos comentarios y observaciones ofrecidos por un árbitro de Estudios de Economía. Sin duda alguna, los mismos contribuyeron a mejorar significativamente este trabajo. También le agradece a Nancy García Vázquez (El Colegio de Jalisco) por su lectura a los borradores del mismo.

** Email: antoniop@cucea.udg.mx Dirección: Departamento de Métodos Cuantitativos. Universidad de Guadalajara, CUCEA. Periférico Norte 799, Núcleo Universitario Los Belenes, 45100, Zapopan, Jalisco, México. Tel: ++ (52) (33) 3770 3300, Ext. 5291. Fax: ++ (52) (33) 3770 3300, Ext. 5227. 
leader-follower relationships are allowed in the banking system. Even government revenues, due to privatization, are higher when these relationships exist.

Key words: Banking, privatization, competition, performance, deposits.

JEL Classification: $G 21, D 43, D 92$.

\section{INTRODUCCIÓN}

En las últimas tres décadas se ha registrado una oleada de privatizaciones sin precedentes en todo el mundo. Sin embargo, históricamente la propiedad de la banca comercial ha sido pública (Megginson, 2005a). Esta situación explica por qué la privatización de los bancos suscita álgidas controversias y debates entre los hacedores de políticas económicas, la academia y la sociedad. Dichas controversias abarcan temas como las razones que justifican la privatización de los bancos, los métodos para llevarla a cabo de una manera adecuada, y los efectos de estas privatizaciones sobre la economía. En la práctica existen muy pocos consensos alrededor de tales cuestiones.

Paradójicamente, la investigación alrededor de las privatizaciones bancarias es escasa. Por una parte, el desarrollo de la teoría económica de la privatización -a contracorriente de la creencia popular-, es relativamente incipiente y no concluyente. Por otra parte, existe escasa disponibilidad de información bancaria pertinente tanto para economías desarrolladas como emergentes. Hasta donde sabemos, los primeros tratados acerca de la privatización bancaria y el futuro de las instituciones financieras públicas son los trabajos de Megginson (2005a) y (2005b) y Caprio et al. (2005). Sin embargo, ninguno de estos tiene un enfoque estrictamente teórico.

En este artículo desarrollamos un marco conceptual formal para estudiar las privatizaciones bancarias desde un enfoque microeconómico. Éste nos sirve para analizar los criterios que las justifican y conocer las consecuencias de la privatización cuando se permiten diferentes regulaciones en los bancos privatizados. Los criterios incluyen consideraciones de eficiencia y estabilidad financiera, de poder de mercado y de calidad de los servicios bancarios. Las regulaciones analizadas se refieren a las estrategias de competencia permitidas en la banca. ${ }^{1}$ En la práctica estos criterios y regulaciones se ubican en el centro de las controversias en torno a la privatización.

Aquí estudiamos la relación entre la privatización, la competencia y el desempeño bancarios. Concretamente, analizamos la conveniencia y consecuencias de la privatización cuando se permiten distintas estrategias de competencia en

1 En la literatura económica, y nuevamente a contracorriente de la creencia popular, son muy escasos los argumentos a favor de promover la libre competencia bancaria. De hecho, a diferencia de lo que ocurre con las firmas no financieras, el laissez-faire en la banca ha sido una de las propuestas más cuestionadas incluso entre aquellos que tradicionalmente apoyan al libre mercado. Una síntesis de los principales argumentos a favor de la competencia en la banca se halla en Dowd (1996). 
el mercado de depósitos. Para ello, usamos las siguientes preguntas como guías de esta investigación: ¿cuáles son los criterios y condiciones que justifican la conveniencia de la privatización?, ¿cómo impactan las estrategias de competencia y los costos de privatizar a la banca privatizada?, ¿qué estrategias de competencia serían deseables en la banca privatizada?, ¿cuáles son los efectos de la privatización bancaria en la economía?

Analíticamente el estudio se aborda mediante la construcción de dos modelos microeconómicos que describen a sistemas bancarios privatizados que sólo difieren en las estrategias de competencia. Concretamente, el primer modelo describe una situación donde hay bancos idénticos que compiten tomando decisiones simultáneas. El segundo modelo describe una situación donde se permiten relaciones líder-seguidor entre los bancos. En ambos modelos se asume que hay competencia oligopólica y riesgos de liquidez en el corto plazo. Además, se supone que el gobierno recibe ingresos por la venta de los bancos privatizados.

Estos modelos microeconómicos se construyen con base en lineamientos de la teoría de la firma bancaria (modelo Monti-Klein). Así se asume que la privatización de un monopolio bancario público conlleva a la formación de un oligopolio de bancos competitivos e interdependientes. Estas interdependencias dependen de las estrategias competitivas permitidas en el mercado de depósitos. En ambos modelos estas estrategias definen interacciones y equilibrios de mercado ( $v . g$. el desempeño del sistema bancario privatizado). Las estrategias de competencia analizadas son de tipo Cournot (bancos simétricos), o de tipo Stackelberg (relaciones líder-seguidor). ${ }^{2}$

Es importante enfatizar que ambos modelos microeconómicos se centran en los depósitos (pasivos e insumos bancarios), como variable central de análisis. Ciertamente esto diverge de otros trabajos que analizan la banca y sus efectos en la economía con base en sus actividades crediticias (vinculadas a los activos y productos de los bancos). ${ }^{3}$ Aquí adoptamos este enfoque debido a que este nos permite analizar las consecuencias de la privatización desde la perspectiva de aquellos que defienden la primera "justificación oficial" de las reglamentaciones bancarias, a saber: la protección del público (esencialmente los depositantes) (Freixas y Rochet, 2008).

Conceptualmente, los modelos bancarios también se enmarcan en el trabajo de Diamond y Dybvig (1983). La importancia de este último trabajo es que nos permite analizar uno de los temas más debatidos en torno a los efectos de la

2 Existen algunos estudios empíricos que apoyan la existencia de estrategias competitivas de tipo Cournot y Stackelberg en los mercados de depósitos. Estrategias de tipo Cournot han sido reportadas en Estados Unidos (Berger y Hannan, 1989 y 1992, Calem y Carlino, 1991 y Hutchison, 1995). Estrategias de tipo Stackelberg han sido reportadas en Nicaragua (Revilla, 1996). Recientemente, el sistema bancario chino ha sido analizado usando estrategias de tipo Bertrand, Cournot y Stackelberg (Zhou et al., 2009).

3 Tradicionalmente los estudios que analizan las privatizaciones bancarias se han centrado en el crédito. Entre estos estudios destacan aquellos que analizan la relación entre el otorgamiento y repago de créditos, la estabilidad macroeconómica y la regulación financiera. Véase a McKinnon (1993) para una síntesis y referencias a esta literatura. 
privatización: la fragilidad financiera de los bancos. ${ }^{4}$ Por esta razón los modelos de privatización aquí desarrollados incorporan varios de los supuestos del marco de Diamond y Dybvig. Metodológicamente estos supuestos permiten: 1) analizar la estabilidad financiera y el desempeño global de los sistemas bancarios; 2) integrar al análisis las conductas de los depositantes; y 3) complementar los análisis tradicionales que se centran en los activos bancarios (créditos).

Los modelos nos permiten evaluar cómo las diferentes regulaciones competitivas afectan al desempeño de los bancos privatizados, a los ingresos gubernamentales por privatizar y a los depositantes. Dicha evaluación se realiza mediante indicadores de eficiencia, estabilidad financiera, poder de mercado y calidad de los servicios bancarios. Los modelos nos permiten, además, calcular la cantidad total de depósitos en la banca y los ingresos del gobierno asociados a la privatización. Más aún, también nos muestran cómo los precios de venta de los bancos privatizados, los parámetros de la oferta de depósitos y las creencias de los depositantes afectan a los sistemas bancarios.

Los resultados del análisis sugieren que la privatización de los bancos es justificable si se cumplen ciertas condiciones económicas. Estas condiciones incluyen consideraciones de eficiencia y estabilidad de los bancos privatizados, así como de poder de mercado y calidad de sus servicios. Otras condiciones incluyen el cumplimiento de prácticas competitivas estables y de ciertas relaciones que envuelven a parámetros exógenos a la banca. Entre estos últimos se incluyen los costos de privatizar y el comportamiento de los depositantes. En consecuencia, el análisis nos muestra que la conveniencia y consecuencias de la privatización dependen de todos los agentes en la economía.

El análisis microeconómico apoya la hipótesis de que las estrategias de competencia explican en buena medida el desempeño de la banca privatizada. Más aún, el análisis sugiere que la privatización bancaria es más sencilla de justificar desde una perspectiva económica, cuando hay relaciones líder-seguidor que cuando hay bancos idénticos. Esto ocurre porque las relaciones líder-seguidor inducen relativamente mayores niveles de eficiencia bancaria y estabilidad financiera, de retornos y disponibilidad de consumo para los depositantes. Incluso el análisis muestra que los ingresos gubernamentales por privatizar son más altos cuando se permiten estas relaciones en la banca.

Las contribuciones de esta investigación se ubican en las literaturas de la microeconomía y privatización bancarias. Concretamente, este trabajo provee un marco para estudiar la conveniencia, formas y consecuencia de privatizar a los intermediarios. ${ }^{5}$ Una segunda contribución consiste en complementar, desde una perspectiva micro, a los estudios macroeconómicos tradicionales sobre la relación entre la liberalización financiera, la privatización y las crisis bancarias. ${ }^{6}$ Finalmente, una tercera contribución consiste en mostrar cómo la

4 Entre los argumentos en contra de privatizar bancos está asociado a la correlación positiva entre las privatizaciones bancarias y la exposición al riesgo de los bancos privatizados en economías emergentes. Esta correlación tiende a ocurrir cuando los bancos son controlados por grupos industriales locales (Boubakri et al., 2005).

5 El estudio pionero de estas relaciones es el de Saha y Sensarma (2004). En el mismo se analiza el grado óptimo de privatización cuando hay un oligopolio mixto en la banca.

6 Fry (1995) ofrece una introducción a los estudios que vinculan la liberalización y crisis bancarias. 
relación entre la competencia y la regulación influye en el desempeño de los sistemas bancarios privatizados. ${ }^{7}$

Este trabajo se organiza en ocho secciones. En la sección 2 se revisa la literatura. En la sección 3 se describe el modelo de (Diamond y Dybvig, 1983). En la sección 4 se describe el sistema bancario monopólico gubernamental. En la sección 5 se desarrolla el modelo de la privatización cuando se permiten bancos simétricos. En la sección 6 se desarrolla el modelo cuando se permiten relaciones líder-seguidor. La sección 7 incluye la estática comparativa y se comparan ambos modelos de privatización bancaria. En la última sección se sintetizan y discuten los resultados. En los apéndices se incluyen las derivadas que sustentan el análisis microeconómico.

\section{El Análisis Económico de las Privatizaciones Bancarias}

Los estudios que han analizado la conveniencia de los regímenes de propiedad pública y privada en la banca abarcan los ámbitos macro y microeconómicos. Tradicionalmente, los estudios que han tendido a defender la propiedad estatal son de tipo macroeconómico (véase Fry, 1995 y Megginson, 2005a). En estos, usualmente se racionaliza la propiedad pública de las instituciones financieras en términos de alcanzar y balancear objetivos social y económicamente deseables. Sin embargo, estos estudios no son los que prevalecen ni los que tienen mayor desarrollo en la literatura. Actualmente, la mayoría de los estudios concernientes a la privatización son microeconómicos.

Megginson (2005a) clasifica la literatura microeconómica sobre las privatizaciones bancarias en tres vertientes: La primera incluye estudios referidos a la conveniencia de privatizar. La segunda incluye a aquellos que estudian los métodos de privatizar bancos. La tercera incluye estudios que analizan los efectos de las privatizaciones. Existe un desarrollo teórico y empírico desigual en estas vertientes. Si bien hay una amplia literatura teórica y empírica referente a los estudios de la primera vertiente, esto no ocurre así en lo que se refiere a las otras dos. Hasta donde sabemos, los estudios correspondientes a estas últimas vertientes son primordialmente empíricos. ${ }^{8}$

La teoría económica de la privatización, en términos generales, se enfoca en los justificantes de la misma (Sheshinski y López-Calva, 2003). Entre los argumentos que se usan para justificarla se encuentran la existencia de problemas de incentivos y contractuales en las empresas públicas. Asimismo se argumenta en términos de restricciones presupuestales "laxas", que inducen a los administradores públicos a malgastar los recursos y a no temer a la bancarrota. Así, la privatización se justifica porque la misma induce eficiencia en las firmas y mejoras en las finanzas públicas. Sin embargo, justo es reconocer que las premisas de esta teoría han sido muy cuestionadas.

7 Véase Carletti (2008), para una revisión de la literatura entre la regulación y competencia bancarias.

8 Clarke, Cull y Shirley (2005) y Megginson (2005a) y (2005b) hacen extensivas revisiones de la literatura empírica de la privatización bancaria. 
Particularmente, las privatizaciones bancarias se justifican con base en la economía de la información y la economía política (Megginson, 2005a)]. Entre los argumentos más usados están aquellos que aducen que los administradores públicos no tienen incentivos para maximizar ingresos, ni para minimizar costos. También se argumenta que en las empresas públicas hay escaso monitoreo y pocas medidas de disciplina por parte de la sociedad. Otros justifican las privatizaciones con base en la hipótesis de que en las empresas públicas hay redistribuciones de recursos dependientes de criterios políticos.

Una limitación clara de estas últimas teorías es que, en realidad, no consideran las características únicas de los bancos. Entre otras, estas incluyen la naturaleza intangible, y no monetariamente cuantificable, de los productos bancarios y la coexistencia de pasivos líquidos y activos no líquidos (véase Heffernan, 2005). Tales características hacen que el análisis de las privatizaciones bancarias, así como de sus métodos y efectos sea diferente al de las firmas no financieras. De hecho, en la literatura casi no hay análisis teóricos centrados en las firmas financieras. En su mayoría, los análisis bancarios sólo describen casos de privatización no siempre exitosos. ${ }^{9}$

Estas consideraciones sugieren que los estudios teóricos de las privatizaciones bancarias deberían fomentarse tanto por razones académicas, gerenciales y de política económica y financiera. La necesidad de estos estudios se hace manifiesta si se consideran las consecuencias económicas de los problemas bancarios. A nivel macro, dichos problemas afectan directamente al ahorro y la inversión y, por añadidura, el crecimiento económico de largo plazo. Asimismo, afectan a los sistemas de pagos y la estabilidad financiera de las economías. A nivel micro, estos afectan a los depositantes, accionistas y prestatarios bancarios; y también a otras firmas financieras y no financieras.

Tales consideraciones explican por qué la literatura teórica de la privatización bancaria usualmente se relaciona con aquella del desarrollo económico. En esa última, la privatización de los intermediarios financieros usualmente se analiza en el contexto de la hipótesis de la "liberalización financiera" (véase McKinnon, 1973 y Shaw, 1973). En esta hipótesis se asume que la eliminación de las distorsiones de mercado en el ámbito financiero (represión financiera) induce el crecimiento en las economías en desarrollo. Particularmente, en esta literatura la privatización de los bancos es vista como una medida de liberalización (Demirguc-Kunt y Detragiache, 1998).

Sin embargo, en la literatura del desarrollo no existen consensos unánimes acerca de la conveniencia de la liberalización financiera (Fry, 1995). Algunos con buenas razones argumentan que la misma promueve crisis sistémicas (véase Díaz-Alejandro, 1985 y Demirguc-Kunt y Detragiache, 1998). Ante esta situación, Fry (1997) señala que la evidencia sugiere que la liberalización depende de ciertos "hechos estilizados" de tipo microeconómico. Destacan entre los mismos: 1) La existencia de una adecuada regulación y supervisión de los bancos; 2) la

$9 \quad$ Véase, entre otros, a Vérgara (1996), Haber (2005) y Wu y Parker (2007). Estos estudian las experiencias chilena, mexicana y taiwanesa, respectivamente. Otchere (2005) hace una revisión de casos con énfasis en economías en desarrollo. Hasta donde sabemos, los escasos estudios teóricos sobre las privatizaciones bancarias se enmarcan en la literatura de los oligopolios mixtos. 
estabilidad de precios; y 3) una conducta competitiva de los bancos orientada hacia la maximización de ganancias.

La mayor limitación de la teoría de la liberalización radica en que no tiene fundamentos microeconómicos sólidos. ${ }^{10}$ Esta limitación es relevante porque la propiedad pública de los intermediarios se ha defendido en términos de fallas de mercado (Stiglitz, 1994). Esta crítica sugiere que la investigación teórica debería considerar que los mercados bancarios se caracterizan por estas fallas (poder de mercado, externalidades, problemas informacionales). Más aún, si se considera que las crisis y algunas regulaciones bancarias se justifican con base en estas fallas, la pertinencia de desarrollar análisis de la privatización con un enfoque microeconómico se justifica plenamente.

Así, esta revisión nos ha mostrado que la teoría de las privatizaciones bancarias podría desarrollarse mediante un enfoque microeconómico. Por estas razones, aquí desarrollamos un marco conceptual formal que considere, en su diseño, la existencia de los llamados hechos estilizados de tipo microeconómico, las fallas de mercado, las regulaciones y las crisis bancarias. Este marco lo usaremos para analizar las razones que justifican la privatización de los bancos, los métodos para llevar a cabo una privatización adecuada y los posibles efectos de estas privatizaciones. Esto con el objetivo de mostrar los alcances y límites de los procesos de privatización en el ámbito bancario.

\section{Las Conductas de los Depositantes y Bancos y los Equilibrios BANCARIOS}

En esta sección planteamos una versión simplificada del modelo bancario de Diamond y Dybvig (1983). El modelo describe cómo la estructura financiera, las conductas de los depositantes y los retornos pagados inciden en la estabilidad y desempeño global de los bancos. En virtud de que el modelo enfatiza el rol de las fallas de mercado (externalidades, problemas informacionales), el mismo nos brinda elementos para estudiar la relación entre las fallas de mercado y las crisis bancarias. Más aún, nos permite plantear el contexto del análisis microeconómico de la privatización.

Concretamente, y al igual que en Diamond y Dybvig (1983), se supone que en la economía hay tres períodos $T=0,1,2$ y un bien homogéneo que puede consumirse o ahorrarse. En esta economía existe un continuo de depositantes dotados de una unidad de dicho bien en el período $T=0$. Este bien puede consumirse en los períodos $T=1$ o $T=2$. Hay dos tipos de depositantes: Los de corto plazo, "tempraneros", que consumen en $T=1$ y los de largo plazo, "maduros", que consumen en $T=2$. El consumo del bien depende de requerimientos de liquidez de los depositantes, que en $T=0$ son desconocidos. Así, ex ante, los depositantes son idénticos.

El consumo de los depositantes determina su utilidad. Los depositantes tempraneros tienen una función de utilidad $u\left(c_{1}\right)$ y los depositantes maduros

10 Los hechos estilizados indicados por Fry (1997) se basan en observaciones empíricas. 
una función $u\left(c_{2}\right) \cdot{ }^{11}$ Estas funciones son "bien portadas" y en todas partes satisfacen la "condición de aversión al riesgo" $-c u^{\prime \prime}(c) / u^{\prime}(c) \geq 1 .{ }^{12}$ Por tanto, los depositantes resultan adversos al riesgo. Sin embargo, dado que en $T=0$ ignoran su tipo, ellos toman sus decisiones con base en la utilidad esperada asumiendo con probabilidad $\Theta$ que serán tempraneros y con probabilidad $1-\Theta$ que serán maduros. Así la función de utilidad esperada, que servirá de base a las decisiones de cada depositante, es $E U=\Theta u\left(c_{1}\right)+(1-\Theta) u\left(c_{2}\right)$.

Las formas de ahorro disponibles en la banca determinan el consumo de los depositantes bancarios. Suponemos que en esta economía hay dos formas de ahorro ofrecidas por los bancos. La primera forma consiste en un depósito de corto plazo que permite transferir el bien de un período a otro sin ningún costo. La segunda consiste en un depósito de largo plazo, sin riesgo, que ofrece un retorno de $R>1$ unidades en $T=2$, pero cuyo rendimiento es nulo si se liquida en $T=1$. La decisión de los depositantes en cuanto a las formas de ahorrar (y consumir) se toma en el período $T=0$.

Los depósitos de largo plazo permiten a los bancos otorgar préstamos para financiar proyectos de largo plazo que no conllevan riesgo. Estos préstamos tienen un retorno fijo $r_{L}>R .{ }^{13} \mathrm{Su}$ principal característica es que son completamente ilíquidos en el corto plazo. El balance general del banco se integra por activos no líquidos y pasivos líquidos. Esta estructura financiera explica la fragilidad financiera de la banca y justifica la necesidad de prácticas de administración de riesgos. Más aún, explica la necesidad de los bancos y los depositantes de tomar decisiones óptimas.

Diamond y Dybvig hallan la solución óptima para las decisiones de los depositantes mediante un contrato bancario de depósitos a la vista definido como sigue; a cambio de un depósito de una unidad en el período $T=0$, los depositantes obtienen una cantidad $c_{1}^{*}$ en el período $T=1$ o $c_{2}^{*}$ en el período

11 Por simplicidad asumimos un factor de descuento intertemporal unitario. Es de destacarse que los resultados cualitativos del análisis no cambian si se asume un factor menor o igual a uno, tal como ocurre en el modelo original de Diamond y Dybvig.

12 El lado izquierdo de esta condición es el coeficiente de Arrow-Pratt de aversión relativa al riesgo. La desigualdad impuesta a dicho coeficiente descarta que la aversión relativa al riesgo sea creciente. Es importante hacer notar que Diamond y Dybvig (1983) suponen que este coeficiente es estrictamente mayor a la unidad. Este supuesto lo introducen para justificar la necesidad de los bancos en la economía. Cuando este coeficiente es mayor a la unidad, se puede mostrar que sólo los intermediarios son capaces de proveer asignaciones de riesgo y consumo óptimas para los agentes. Cuando la condición es unitaria, los bancos y mercados financieros son igualmente capaces de proveer dichas asignaciones (Freixas y Rochet, 2008).

13 Un retorno fijo para los préstamos supone que hay una demanda perfectamente elástica de créditos y que no hay riesgo crediticio. Existe alguna evidencia de que demandas muy elásticas pudieran existir en economías que experimentan procesos de liberalización financiera. Sin embargo, bien puede argumentarse que la ausencia de riesgo crediticio ignora la correlación positiva que usualmente se da entre el riesgo y el crédito otorgado. En consecuencia, el supuesto ciertamente es restrictivo. Sin embargo, aquí lo adoptamos porque nos permite centrar el análisis microeconómico en los pasivos bancarios. 
$T=2$. Estas cantidades conforman la asignación óptima que deviene de resolver el siguiente problema de optimización:

$$
\begin{gathered}
\operatorname{Max}_{c_{1}, c_{2}} \quad E U=\Theta u\left(c_{1}\right)+(1-\Theta) u\left(c_{2}\right) \\
\text { s.a } \\
\Theta c_{1}+(1-\Theta) \frac{c_{2}}{R}=1
\end{gathered}
$$

donde la segunda expresión es la restricción presupuestal esperada del depositante.

El problema de optimización asume que el banco provee a los depositantes de un seguro contra choques idiosincráticos de liquidez que afectan a sus necesidades de consumo. Matemáticamente la solución óptima de dicho problema $\left(c_{1}^{*}, c_{2}^{*}\right)$ satisface la condición de primer orden $R u^{\prime}\left(c_{2}\right)=u^{\prime}\left(c_{1}\right) \cdot{ }^{14}$ Esta condición puede reescribirse como:

$$
R=\frac{u^{\prime}\left(c_{1}\right)}{u^{\prime}\left(c_{2}\right)}
$$

Esta ecuación la denominamos como la condición de equilibrio del sistema bancario porque, como se verá más adelante, induce el equilibrio prevaleciente en la banca.

A manera de ilustración, aquí estimamos la asignación óptima de consumo para un caso específico. Supongamos que la función de utilidad de los depositantes es logarítmica $u\left(c_{i}\right)=\ln \left(c_{i}\right)$. Así la función esperada de utilidad es $E U=\Theta \ln \left(c_{1}\right)+(1-\Theta) \ln \left(c_{2}\right)$. Dada esta función, la solución óptima satisface la condición de primer orden $c_{2}^{*}=R c_{1}^{*}$. Si sustituimos a $c_{2}^{*}$ en la restricción presupuestal esperada del depositante, ocurre que $c_{1}^{*}=1$. Si ahora sustituimos a $c_{1}^{*}$ en la condición de primer orden ocurre que $c_{2}^{*}=R$. Así, la asignación de óptima de consumo queda como $\left(c_{1}^{*}, c_{2}^{*}\right)=(1, R) \cdot{ }^{15}$

14 Esta ecuación se obtiene en dos pasos. Primeramente se deriva la función lagrangiana del problema de optimización con respecto a las variables de consumo y se igualan las derivadas parciales resultantes a cero. La condición se obtiene tras despejar el multiplicador de Lagrange asociado a ambas derivadas.

15 Esta asignación óptima está asociada a que el coeficiente de Arrow-Pratt de la función de utilidad logarítmica es unitario. Si la función de utilidad fuera diferente, y el coeficiente fuera mayor a uno, el cumplimiento de la condición de equilibrio tendería a incrementar el consumo de corto plazo y a reducirlo en el largo plazo. Esto es, ocurriría que $c_{1}^{*}>1 \mathrm{y}$ $c_{2}^{*}<R$ (véase la nota 3 en Diamond y Dybvig, 1983). Particularmente, la condición de equilibrio implicaría que $c_{2}^{*}=c_{2}^{*}(R)$ bajo cualquier función de utilidad. Además, por la misma condición, siempre ocurriría que $c_{2}^{*}>c_{1}^{*}$. Enfatizamos estos últimos hechos porque los mismos también ocurren cuando el coeficiente de Arrow-Pratt es unitario. En esta consideración se basa nuestra creencia de que los resultados cualitativos del análisis no se alterarían de modificarse la función de utilidad. El caso aquí analizado, con agentes 
El retorno de los depósitos de largo plazo $R$ es muy importante para los bancos y los depositantes maduros. Para los primeros es el costo necesario para atraer depósitos. Para los segundos, es un indicador de su consumo y utilidad. En este contexto, las creencias de los depositantes sobre la confiabilidad bancaria son de vital importancia. Por ejemplo, si un depositante maduro considera que el banco cumplirá con sus obligaciones, él puede elegir entre retirar $c_{2}^{*}$ en $T=2$ o retirar $c_{1}^{*}$ en $T=1$ y almacenar el bien hasta $T=2$. Esto es, él elegirá entre continuar o no continuar con el proceso de intermediación bancaria.

En general, la estabilidad o inestabilidad del sistema bancario depende de la conducta de los depositantes maduros. Si ellos confían en el banco y $R \geq 1$, hay un equilibrio eficiente con estabilidad financiera. Sin embargo, si ellos no confían o $R<1$, resulta racional retirar sus depósitos. En este último caso ocurre una situación en donde los depositantes tempraneros y maduros retiran simultáneamente sus depósitos, quebrando con ello al banco y eventualmente al sistema bancario. ${ }^{16}$ Esta situación, denominada como corrida bancaria, es una situación de equilibrio ineficiente.

Las creencias de los depositantes maduros y la condición de equilibrio (2) determinan el tipo de equilibrio en estrategias puras prevaleciente en la banca. La conducta de los depositantes depende de la seguridad que tengan en el banco con respecto a su capacidad para cumplir con sus obligaciones contractuales. La condición de equilibrio depende de la estructura del mercado. Si los retornos de los depósitos de largo plazo son elevados, estos inducirán equilibrios bancarios eficientes (estabilidad financiera). Si los retornos son bajos o no creíbles, estos inducirán equilibrios ineficientes (corridas bancarias).

Finalizamos esta sección enfatizando cómo interactúan los retornos de largo plazo $R$ y la condición de equilibrio en la determinación de los equilibrios bancarios. Como ya se ha indicado, si ocurriera que $R<1$, el equilibrio ineficiente resultaría racional dado que el consumo óptimo de los depositantes maduros sería menor que el de los tempraneros. Hasta ahora hemos asumido que $R$ es un parámetro constante mayor a uno. Sin embargo, si el valor de $R$ no fuera constante bien podría ocurrir que el equilibrio prevaleciente fuera el ineficiente. Esta posibilidad es la que motiva los análisis subsecuentes.

\section{El Sistema Bancario Cuando Existe un Monopolio Gubernamental}

Diamond y Dybvig (1983) asumen que el retorno de los depósitos de largo plazo $R$ es un parámetro exógeno. Esto ocurre debido a que ellos consideran la

que poseen una utilidad logarítmica, es un caso límite, mas no diferente, de los analizados por Diamond y Dybvig (1983).

16 Adviértase que la quiebra del sistema bancario puede ocurrir como efecto del pánico de los depositantes, no necesariamente de la mala administración de los bancos. Esto es un efecto de externalidad. 
existencia de un monopolio bancario que tiene una conducta meramente pasiva. Un supuesto más realista es suponer que el banco ejerce su poder de mercado para maximizar ganancias. Aquí, para efectos del análisis de la privatización, asumiremos que dicho monopolio es del gobierno y que el monopolio ejerce su poder en el mercado de insumos bancarios (depósitos). Por tanto, ahora ocurre que $R=R(D)$.

Supongamos, en línea con los hechos estilizados de Fry (1997), que el banco gubernamental maximiza sus ganancias de largo plazo. Concretamente, en el período $T=0$, el banco monopólico elige y asigna la cantidad de depósitos que le retribuirán ganancias óptimas en $T=2$. Así el total de depósitos bancarios se determina de acuerdo a las condiciones del mercado. Además, dados los supuestos con respecto a los depositantes, formas de ahorro y al contrato bancario, el banco almacena $\Theta c_{1}^{*}$ de los depósitos de cada depositante y utiliza el resto para financiar préstamos de largo plazo. ${ }^{17}$

Matemáticamente la función de ganancias bancarias a maximizar se puede escribir como:

$$
\pi_{M}=r_{L}\left(1-\Theta c_{1}^{*}\right) D_{M}-(1-\Theta) c_{2}^{*} D_{M}
$$

donde $r_{L}\left(1-\Theta c_{1}^{*}\right) D_{M}$ son los ingresos asociados a los préstamos otorgados en $T=0$ y $(1-\Theta) c_{2}^{*} D_{M}$ los costos de largo plazo. Esto ocurre debido a que en el corto plazo el banco tiene ingresos y costos iguales a $\Theta c_{1}^{*} D_{M}$. Esto implica que el banco sólo puede recibir ingresos sobre una fracción $1-\Theta c_{1}^{*}$ de sus depósitos en $T=0$. En lo que a los costos se refiere, estos son suficientes para satisfacer las exigencias de los depositantes maduros.

El banco monopólico maximiza ganancias en el largo plazo. Esto significa que el banco les pagará a los depositantes la asignación óptima $\left(c_{1}^{*}, c_{2}^{*}\right)$, sólo cuando ocurra un equilibrio eficiente. Asumimos, al igual que en la sección anterior, que los depositantes tienen una función de utilidad logarítmica y que existe una función de oferta de depósitos lineal $R(D)=a+b(D)$, donde $a>0$ y $b>0$ constantes. Bajo estos supuestos, y tras un poco de álgebra, podemos reescribir el programa de optimización como:

$$
\underset{D_{M}}{\operatorname{Max}} \pi_{M}=(1-\Theta)\left[r_{L}-\left(a+b D_{M}\right)\right] D_{M}
$$

Matemáticamente, la condición de primer orden nos permite determinar la cantidad óptima de depósitos y el retorno de equilibrio para los depositantes de largo plazo. En el caso analizado, dicha condición es

17 Esta asignación garantiza el cumplimiento de las obligaciones contractuales de los bancos cuando hay un equilibrio con estabilidad financiera. Más aun, explica la racionalidad de las reservas fraccionarias en los sistemas bancarios. 
$(1-\Theta)\left[r_{L}-R\left(D_{M}^{*}\right)-b D_{M}^{*}\right]=0 .{ }^{18}$ Esta condición permite obtener el total de depósitos introduciendo en la misma a la función de oferta. Y despejando la variable $D_{M}^{*}$. Así, el total de depósitos en el sistema monopólico es:

$$
D_{M}^{*}=\frac{r_{L}-a}{2 b}
$$

El total de depósitos permite determinar el retorno de los depósitos de largo plazo. Este retorno se obtiene sustituyendo la expresión (5) en la función de oferta. Así, en el período $T=0$, cuando existe un monopolio gubernamental en el sistema bancario, los retornos de equilibrio ofrecidos a los depositantes maduros son:

$$
R\left(D_{M}^{*}\right)=\frac{r_{L}+a}{2}
$$

Los beneficios del gobierno asociados a las actividades de intermediación del banco monopólico se estiman con los depósitos totales. Estos beneficios se evalúan sustituyendo las expresiones (5) y (6) en la función de ganancias, (3). Así ocurre que el total de ganancias en el sistema bancario gubernamental es:

$$
\pi\left(D_{M}^{*}\right)=(1-\Theta)\left(\frac{\left(r_{L}-a\right)^{2}}{4 b}\right)
$$

Asimismo es posible calcular los consumos óptimos de los depositantes. Si se sustituye (6) en la asignación óptima de consumo $\left(c_{1}^{*}, c_{2}^{*}\right)$, dados los supuestos sobre la utilidad logarítmica de los depositantes, ocurre que:

$$
\begin{gathered}
c_{1}^{*}\left(D_{M}^{*}\right)=1 \\
c_{2}^{*}\left(D_{M}^{*}\right)=\frac{r_{L}+a}{2}
\end{gathered}
$$

El análisis del monopolio bancario gubernamental puede completarse mediante el análisis de estática comparativa. ${ }^{19}$ Este análisis nos muestra que un incremento en los retornos de los préstamos aumenta el total de depósitos y

18 Esta condición se obtiene tras derivar la función de ganancias con respecto a la cantidad de depósitos e igualando el resultado a cero.

19 Las derivadas parciales que sustentan estas afirmaciones están en el Apéndice A. 
ganancias bancarias, el retorno de los depósitos de largo plazo y el consumo de los depositantes maduros. Además, el análisis nos muestra que un incremento en la proporción de depositantes tempraneros reduce las ganancias bancarias monopólicas. Estos resultados, en su conjunto, sugieren que una mejor administración bancaria tiene efectos benéficos que trascienden a los bancos.

Los resultados anteriores son una referencia para el análisis económico del desempeño de la banca gubernamental. Hasta ahora hemos indicado algunos resultados intuitivamente plausibles. Sin embargo, el análisis muestra otros no tan evidentes [véase Apéndice A]. Entre estos últimos destaca que un incremento en los parámetros de la oferta de depósitos reduce el total de los mismos, así como las ganancias bancarias. Otro resultado sugiere que un incremento en el parámetro de la ordenada al origen de la oferta aumenta el retorno de largo plazo y el consumo de los depositantes maduros.

Estos resultados son una referencia para analizar la conveniencia y efectos de privatizar la banca. Hasta este momento hemos descrito qué ocurre en el sistema bancario cuando hay un monopolio gubernamental. En las siguientes secciones estudiaremos qué ocurre cuando este monopolio se fragmenta y se permiten diversas estrategias competitivas en un oligopolio de bancos privatizados. En este contexto asumiremos que las fallas microeconómicas (poder de mercado, externalidades, problemas informacionales) no desaparecen con la privatización. Esto con fines de comparación y análisis.

\section{El Análisis de la Privatización Bancaria Cuando se Permiten Estrategias de Tipo Cournot y Bancos Simétricos}

En esta sección analizamos la privatización cuando se permiten bancos simétricos que compiten simultáneamente por depósitos (insumos bancarios). Particularmente a las estrategias competitivas permitidas las denominamos como de tipo Cournot. Cuando existen estas estrategias ocurre que: 1) Cada banco del sistema es consciente de que su propia demanda de depósitos incrementa el retorno pagado por los depósitos de largo plazo; y 2) Cada banco asume que las decisiones de sus competidores son fijas. En consecuencia, cada banco elige su demanda óptima, dadas las decisiones de los otros.

Las estrategias Cournot son muy útiles en la teoría microeconómica de la banca porque incluyen como casos límite, al monopolio y la competencia perfecta (Freixas y Rochet, 2008). Estos casos son usados como referencia para evaluar la competencia y eficiencia en las industrias, así como para evitar la concentración en los mercados. En la teoría de la firma, el supuesto de la simetría se usa para modelar que no haya "desequilibrios" entre las firmas (v.g. los bancos privatizados). Estas consideraciones son las que justifican el uso de estrategias competitivas de tipo Cournot con bancos simétricos.

En el sistema bancario donde se permiten estrategias de tipo Cournot, cada banco elige, de manera simultánea a los demás, la cantidad de depósitos que le permitirá maximizar sus ganancias. Concretamente aquí suponemos que la 
privatización conlleva a la formación de un oligopolio integrado por dos bancos, $i$ y $j .{ }^{20}$ En este contexto, la función de ganancias a maximizar en el largo plazo del banco $i$ es:

$$
\pi_{i}=r_{L}\left(1-\Theta c_{1}^{*}\right) D_{i}-(1-\Theta) c_{2}^{*} D_{i}-G\left(D_{i}\right)
$$

donde $G\left(D_{i}\right)$ es el pago al gobierno por privatizar el banco $i$.

La función $G\left(D_{i}\right)$ indica el precio de venta de los bancos. Asumimos que este precio es una proporción constante del total de depósitos del banco privatizado $0<P<1 .{ }^{21}$ En consecuencia, en $T=2$, los ingresos del gobierno por privatizar al banco $i$ son $G\left(D_{i}\right)=P D_{i}$. Este supuesto define el programa de optimización del banco $i$. Dados los supuestos asociados a un equilibrio eficiente y una función de oferta de depósitos lineal, el programa de optimización queda como:

$$
\underset{D_{i}}{\operatorname{Max}} \pi_{i}=(1-\Theta)\left[r_{L}-\left(a+b\left(D_{i}+D_{j}\right)\right)\right] D_{i}-P D_{i}
$$

El planteamiento del programa refleja algunos hechos que se aduce que realmente ocurrieron en Latinoamérica (México) en los años noventa (véase Haber, 2005). Por ejemplo, se considera que el costo de la privatización $G\left(D_{i}\right)$ se paga con los ingresos de largo plazo de los bancos privatizados. Asimismo, el programa considera que una razón financiera fija, y no necesariamente óptima desde la perspectiva de la teoría de valuación de activos, sirve como referencia para valuar los ingresos de la privatización de los bancos. Existe evidencia de que estas razones han sido usadas con este propósito. ${ }^{22}$

El programa (11) permite determinar los depósitos óptimos del banco $i$ y de la totalidad del sistema bancario. La condición de primer orden del programa queda como $(1-\Theta)\left[r_{L}-R\left(D_{i}^{*}\right)-b D_{i}^{*}\right]-P=0$. Asumiendo bancos simétricos, $D_{i}^{*}=D_{j}^{*}$, la cantidad de depósitos óptima del banco $i$ es

20 El modelo es fácilmente generalizable a $n$ bancos. Sin embargo, por simplicidad de exposición, aquí solo nos enfocaremos en el caso más sencillo de oligopolio.

21 El precio de los bancos privatizados usualmente se establece en términos de los activos bancarios. En el contexto del modelo, dada la inexistencia de capital, los pasivos (depósitos) y activos son equivalentes al valor de los bancos. Ciertamente el precio establecido aquí es relativamente bajo. Sin embargo, el mismo se justifica si el proceso de maximización de ganancias se repite bajo condiciones similares durante un número finito de ocasiones y que en cada ocasión se "abona" una parte del costo total de venta.

22 Ortiz-Martínez (1994) hace una descripción detallada de cómo las razones financieras se usaron como referencia para privatizar los bancos mexicanos. Particularmente, este autor indica que el precio de venta de los bancos "medido en su relación precio/utilidad fue de 14,75 veces, en tanto que el múltiplo promedio del valor de mercado/valor en libros fue de 3,068" (Ortiz-Martínez, 1994, 342-343). Resulta de interés señalar que el autor menciona que estas razones fueron muy altas para los estándares internacionales. 
$D_{i}^{*}=\frac{1}{3}\left(\frac{(1-\Theta)\left(r_{L}-a\right)-P}{b(1-\Theta)}\right)$. En consecuencia, el total de depósitos cuando existen bancos simétricos y estrategias de tipo Cournot en el sistema bancario, $D_{C}^{*}=D_{i}^{*}+D_{j}^{*}$, es:

$$
D_{C}^{*}=\frac{2}{3}\left(\frac{(1-\Theta)\left(r_{L}-a\right)-P}{b(1-\Theta)}\right)
$$

La cantidad total de depósitos en el sistema bancario nos permite estimar el retorno de los depósitos de largo plazo y los ingresos del gobierno por privatizar la banca. El retorno de los depósitos $R\left(D_{C}^{*}\right)$ se calcula de manera similar a como se hizo en la sección anterior. Los ingresos por privatizar se calculan sustituyendo el total de depósitos (12) en la función de pago al gobierno por privatizar, $G\left(D_{C}^{*}\right)=P D_{C}^{*}$. Así los retornos de equilibrio para los depositantes maduros y los ingresos del gobierno por privatizar son:

$$
\begin{aligned}
& R\left(D_{C}^{*}\right)=\frac{1}{3}\left(\frac{(1-\Theta)\left(2 r_{L}+a\right)-2 P}{(1-\Theta)}\right) \\
& G\left(D_{C}^{*}\right)=\frac{2}{3}\left(\frac{P(1-\Theta)\left(r_{L}-a\right)-P^{2}}{b(1-\Theta)}\right)
\end{aligned}
$$

Los beneficios totales del sistema bancario privatizado se estiman con los depósitos totales de la banca y el retorno de largo plazo. Estos beneficios se calculan sustituyendo (12) y (13) en la función de ganancias individuales, (10). Esto es equivalente a sumar las ganancias de cada uno de los bancos simétricos. Así ocurre que el total de ganancias en el sistema bancario privado cuando existen bancos simétricos y estrategias competitivas de tipo Cournot es:

$$
\pi\left(D_{C}^{*}\right)=\frac{2}{9}\left(\frac{\left((1-\Theta)\left(r_{L}-a\right)-P\right)^{2}}{b(1-\Theta)}\right)
$$

El consumo óptimo de los depositantes tempraneros y maduros es posible calcularlo de manera similar a como se hizo en la sección anterior. Así, si se sustituye (13) en la asignación óptima de consumo $\left(c_{1}^{*}, c_{2}^{*}\right)$ ocurre que:

$$
c_{1}^{*}\left(D_{C}^{*}\right)=1
$$




$$
c_{2}^{*}\left(D_{C}^{*}\right)=\frac{1}{3}\left(\frac{(1-\Theta)\left(2 r_{L}+a\right)-2 P}{(1-\Theta)}\right)
$$

El análisis desarrollado hasta ahora es muy similar al realizado para el caso del monopolio gubernamental. Sin embargo, el mismo, en principio, no justifica la conveniencia de la privatización. La argumentación a favor de esta podría darse en términos de incrementos en la eficiencia en las actividades bancarias. Otra justificación podría darse con base en el incremento de la estabilidad financiera. Otras justificaciones podrían darse con base en reducciones en el poder de mercado (mayores retornos de los depósitos) e incrementos en la calidad de los servicios (mayor consumo disponible). ${ }^{23}$

$\mathrm{El}$ análisis sugiere que la privatización es justificable bajo ciertos criterios económicos. El argumento de la eficiencia implicaría que las ganancias totales en el sistema privado no deberían ser mayores que en el sistema gubernamental. El argumento de la estabilidad financiera implicaría que el retorno pagado a los depositantes de largo plazo no debería disminuir en los bancos privatizados. ${ }^{24}$ Finalmente, los argumentos basados en el poder de mercado y disponibilidad de consumo implicarían que el consumo de los depositantes no debería reducirse en la banca privatizada.

Los argumentos anteriores a favor de la privatización requerirían que los indicadores bancarios estimados cumplieran ciertas desigualdades de tipo económico. Concretamente, el tránsito de un monopolio gubernamental a un oligopolio privado donde se permitieran estrategias de tipo Cournot se justificaría en términos de eficiencia si $\pi\left(D_{C}^{*}\right) \leq \pi\left(D_{M}^{*}\right)$. Asimismo se justificaría en términos de la estabilidad financiera y de poder de mercado si $R\left(D_{C}^{*}\right) \geq R\left(D_{M}^{*}\right)$. Finalmente, se justificaría en términos de la disponibilidad de consumo si $c_{1}^{*}\left(D_{C}^{*}\right) \geq c_{1}^{*}\left(D_{M}^{*}\right)$ y $c_{2}^{*}\left(D_{C}^{*}\right) \geq c_{2}^{*}\left(D_{M}^{*}\right)$.

Matemáticamente estas desigualdades se satisfacen bajo la condición suficiente $(1-\Theta)\left(r_{L}-a\right)-4 P>0$. En este caso, la desigualdad de la eficiencia se cumple porque:

23 Un árbitro señaló que un criterio complementario para justificar la conveniencia de la privatización y las estrategias competitivas en la banca privatizada podría darse en términos de la evaluación del bienestar social (mejoras de Pareto). Coincidimos plenamente con su punto de vista. Un ejercicio de esta naturaleza requeriría evaluar y comparar la suma del excedente del consumidor, el excedente de los bancos y los ingresos del gobierno bajo los distintos escenarios analizados. Si bien se pensó en incluir aquí dicho ejercicio, su extensión y relevancia hicieron evidente que el mismo amerita un trabajo independiente. Por esta razón, en la última sección de este trabajo se explicita que el estudio de las relaciones entre la privatización bancaria y el bienestar social complementaría el análisis aquí desarrollado.

24 Esta condición deviene del hecho de que una disminución de los retornos de largo plazo puede inducir a los depositantes maduros a racionalizar una corrida bancaria. 


$$
\pi\left(D_{C}^{*}\right)-\pi\left(D_{M}^{*}\right)=-\frac{1}{36}\left(\frac{(1-\Theta)^{2}\left(r_{L}-a\right)^{2}+16 P(1-\Theta)\left(r_{L}-a\right)-8 P^{2}}{b(1-\Theta)}\right)<0
$$

La desigualdad de la estabilidad y el poder de mercado, igualmente se cumple.

$$
R\left(D_{C}^{*}\right)-R\left(D_{M}^{*}\right)=\frac{1}{6}\left(\frac{(1-\Theta)\left(r_{L}-a\right)-4 P}{(1-\Theta)}\right)>0
$$

Lo mismo ocurre con las desigualdades del consumo de los depositantes.

$$
\begin{gathered}
c_{1}^{*}\left(D_{C}^{*}\right)-c_{1}^{*}\left(D_{M}^{*}\right)=0 \\
c_{2}^{*}\left(D_{C}^{*}\right)-c_{2}^{*}\left(D_{M}^{*}\right)=\frac{1}{6}\left(\frac{(1-\Theta)\left(r_{L}-a\right)-4 P}{(1-\Theta)}\right)>0
\end{gathered}
$$

Las expresiones (18), (19), (20) y (21) justifican la conveniencia de las privatizaciones bancarias con base en condiciones y criterios económicos. Particularmente, para el caso analizado, podemos sintetizar nuestros resultados en la siguiente proposición:

Resultado 1: Si se cumple la condición suficiente $(1-\Theta)\left(r_{L}-a\right)-4 P>0$ y se permiten estrategias de tipo Cournot en el mercado de depósitos, entonces la privatización de un monopolio bancario a fin de constituir un duopolio con bancos simétricos es justificable según los siguientes criterios: (i) eficiencia, (ii) poder de mercado/estabilidad financiera y (iii) disponibilidad de consumo.

Finalizamos esta sección enfatizando que el análisis justifica la privatización bancaria de manera condicionada. Esto ocurre porque los bancos privatizados deben satisfacer ciertas condiciones regulatorias y de desempeño. Estas condiciones incluyen que se permitan estrategias de tipo Cournot y se cumplan ciertos criterios económicos. También incluyen el cumplimiento de la "condición suficiente" que envuelve parámetros dependientes de los depositantes y el gobierno. En consecuencia, el análisis muestra que la privatización depende, en realidad, de todos los agentes en la economía.

\section{El Análisis de la Privatización Bancaria Cuando se Permiten Estrategias de Tipo Stackelberg y Relaciones Líder-Seguidor}

En esta sección analizamos los efectos de la privatización cuando se permiten bancos líderes y seguidores en el mercado de depósitos. A este tipo de 
estrategias competitivas las denominamos de tipo Stackelberg. Cuando existe este tipo de estrategias en el sistema bancario ocurre que: 1) Inicialmente, dadas las condiciones del mercado, los bancos líderes eligen un nivel de demanda de depósitos y se comprometen a no modificar dicha decisión porque saben que este nivel es el más lucrativo para sí mismos; y 2) Los bancos seguidores eligen la demanda óptima dadas las decisiones de los líderes. ${ }^{25}$

La privatización bajo este tipo de regulación puede ser analizada sin modificar sensiblemente el sistema bancario descrito anteriormente. Así, nuevamente suponemos una oferta de depósitos lineal, depositantes con funciones de utilidad logarítmicas y dos bancos. Asimismo suponemos un precio de venta proporcional al valor de los bancos. La diferencia radica en que ahora hay un banco "líder", $l$, y otro "seguidor", $f$. El banco líder es quien decide primero con base en su capacidad para anticipar las decisiones del banco seguidor. En consecuencia, las decisiones son secuenciales e interdependientes.

Las decisiones secuenciales e interdependencias asociadas a las estrategias de tipo Stackelberg modifican los programas de optimización de los bancos privatizados. El banco líder anticipa y decide antes que el banco seguidor. Así el banco líder, en principio, considera que el banco seguidor deseará maximizar sus ganancias de largo plazo en el período $T=0$. En consecuencia, el líder anticipa que el programa de maximización de ganancias del banco seguidor será:

$$
\underset{D_{f}}{\operatorname{Max}} \pi_{f}=(1-\Theta)\left[r_{L}-\left(a+b\left(D_{l}+D_{f}\right)\right)\right] D_{f}-P D_{f}
$$

El programa de maximización del banco seguidor asume que la decisión óptima del banco líder, $D_{l}^{*}$, estará dada. Este supuesto se refleja en la función de reacción óptima del banco seguidor prevista por el líder. Dicha función, que vincula la decisión óptima del seguidor con las decisiones del líder, se obtiene despejando $D_{f}^{*}$ de la condición de primer orden asociada a (22). Así la función de reacción del banco seguidor queda como:

$$
D_{f}\left(D_{l}^{*}\right)=\frac{1}{2}\left(\frac{(1-\Theta)\left(r_{L}-a-b D_{l}^{*}\right)-P}{b(1-\Theta)}\right)
$$

La función de reacción (23) formaliza la interdependencia entre las decisiones del líder y el seguidor y modifica el programa de maximización del líder. Matemáticamente esto ocurre porque la función de reacción del seguidor restringe

25 En este modelo los bancos líderes tienen la capacidad de comprometerse a un nivel de depósitos al que los seguidores deben adaptarse. Así, la información, experiencia y credibilidad de los líderes resultan importantes. Adviértase que aquí ningún banco "adivina" las decisiones de los otros. 
el área factible asociada a la función objetivo del banco líder. En consecuencia, el programa de optimización de ganancias de largo plazo del líder en el período $T=-1,{ }^{26}$ queda como:

$$
\begin{gathered}
\underset{D_{l}}{\operatorname{Max}} \pi_{l}=(1-\Theta)\left[r_{L}-\left(a+b\left(D_{l}+D_{f}\right)\right)\right] D_{l}-P D_{l} \\
\text { s.a } \\
D_{f}\left(D_{l}\right)
\end{gathered}
$$

La función de reacción (23) y la condición de primer orden del programa de optimización (24) permiten calcular el total de depósitos en el sistema bancario privatizado. La cantidad de depósitos óptima del banco líder, estimada con la condición de primer orden, es $D_{l}^{*}=\frac{1}{2}\left(\frac{(1-\Theta)\left(r_{L}-a\right)-P}{b(1-\Theta)}\right)$. Esta cantidad, sustituida en (23), define los depósitos óptimos del seguidor como $D_{f}^{*}=\frac{1}{4}\left(\frac{(1-\Theta)\left(r_{L}-a\right)-P}{b(1-\Theta)}\right)$. Así, el total de depósitos cuando hay interacciones Stackleberg, $D_{S}^{*}=D_{f}^{*}+D_{l}^{*}$, es:

$$
D_{S}^{*}=\frac{3}{4}\left(\frac{(1-\Theta)\left(r_{L}-a\right)-P}{b(1-\Theta)}\right)
$$

Nuevamente, la cantidad total de depósitos en el sistema bancario, $D_{S}^{*}$, nos permite estimar el retorno de los depósitos de largo plazo, $R\left(D_{S}^{*}\right)$ y los ingresos del gobierno por privatizar, $G\left(D_{S}^{*}\right)$. Estos se calculan de manera similar a como se hizo en la sección anterior. Así, en el período $T=0$, los retornos para los depositantes maduros y el total de ingresos del gobierno, cuando existen interacciones tipo Stackelberg, son los siguientes:

$$
R\left(D_{s}^{*}\right)=\frac{1}{4}\left(\frac{(1-\Theta)\left(3 r_{L}-a\right)-3 P}{(1-\Theta)}\right)
$$

26 El modelo tradicional de Stackelberg supone que las decisiones del líder y el seguidor se realizan en dos tiempos. Esta consideración obliga a ampliar la estructura temporal del modelo a cuatro tiempos $T=-1,0,1,2$. Así, en los períodos $T=-1$ y $T=0$, se toman las decisiones del líder y el seguidor. Adicionalmente, en $T=0$ se determinan las cantidades óptimas de depósitos y los retornos asociados. Así la consistencia temporal y comparabilidad de los modelos bancarios se mantiene. 


$$
G\left(D_{S}^{*}\right)=\frac{3}{4}\left(\frac{P(1-\Theta)\left(r_{L}-a\right)-P^{2}}{b(1-\Theta)}\right)
$$

Los beneficios privados asociados a las actividades de intermediación de los bancos se evalúan como se hizo anteriormente. Así ocurre que el total de ganancias en el sistema bancario cuando existe competencia Stackelberg es:

$$
\pi\left(D_{S}^{*}\right)=\frac{3}{16}\left(\frac{\left((1-\Theta)\left(r_{L}-a\right)-P\right)^{2}}{b(1-\Theta)}\right)
$$

Asimismo, y de manera análoga a como se hizo en la sección anterior, se calculan los consumos óptimos de los depositantes. Así, si se sustituye (26) en la asignación óptima de consumo $\left(c_{1}^{*}, c_{2}^{*}\right)$ ocurre que:

$$
\begin{gathered}
c_{1}^{*}\left(D_{S}^{*}\right)=1 \\
c_{2}^{*}\left(D_{S}^{*}\right)=\frac{1}{4}\left(\frac{(1-\Theta)\left(3 r_{L}+a\right)-3 P}{(1-\Theta)}\right)
\end{gathered}
$$

Nuevamente es posible justificar la privatización con base en los criterios de eficiencia, estabilidad financiera, poder de mercado y disponibilidad de consumo. Como en la sección anterior, dicha justificación se evalúa con base en el cumplimiento de cuatro desigualdades. Así, la privatización bancaria se justificaría en términos de eficiencia si $\pi\left(D_{S}^{*}\right) \leq \pi\left(D_{M}^{*}\right)$. Igualmente se justificaría en términos de la estabilidad financiera y del poder de mercado si $R\left(D_{S}^{*}\right) \geq R\left(D_{M}^{*}\right)$. Finalmente, se justificaría en términos de la disponibilidad de consumo si $c_{1}^{*}\left(D_{S}^{*}\right) \geq c_{1}^{*}\left(D_{M}^{*}\right)$ y $c_{2}^{*}\left(D_{S}^{*}\right) \geq c_{2}^{*}\left(D_{M}^{*}\right)$.

Las anteriores desigualdades se satisfacen bajo la condición suficiente $(1-\Theta)\left(r_{L}-a\right)-3 P>0$. En este caso, la desigualdad de la eficiencia se cumple porque:

$$
\pi\left(D_{S}^{*}\right)-\pi\left(D_{M}^{*}\right)=-\frac{1}{16}\left(\frac{(1-\Theta)^{2}\left(r_{L}-a\right)^{2}+6 P(1-\Theta)\left(r_{L}-a\right)-3 P^{2}}{b(1-\Theta)}\right)<0
$$

La desigualdad de la estabilidad y el poder de mercado también se cumple: 


$$
R\left(D_{S}^{*}\right)-R\left(D_{M}^{*}\right)=\frac{1}{4}\left(\frac{(1-\Theta)\left(r_{L}-a\right)-3 P}{(1-\Theta)}\right)>0
$$

Lo mismo ocurre con las desigualdades del consumo de los depositantes.

$$
\begin{gathered}
c_{1}^{*}\left(D_{S}^{*}\right)-c_{1}^{*}\left(D_{M}^{*}\right)=0 \\
c_{2}^{*}\left(D_{S}^{*}\right)-c_{2}^{*}\left(D_{M}^{*}\right)=\frac{1}{4}\left(\frac{(1-\Theta)\left(r_{L}-a\right)-3 P}{(1-\Theta)}\right)>0
\end{gathered}
$$

Las expresiones (31), (32), (33) y (34) justifican la conveniencia de las privatizaciones bancarias cuando se permiten estrategias competitivas de tipo Stackelberg. Particularmente, podemos sintetizar nuestros resultados en la siguiente proposición:

Resultado 2: Si se cumple la condición suficiente $(1-\Theta)\left(r_{L}-a\right)-3 P>0$ y se permiten estrategias de tipo Stackelberg en el mercado de depósitos, entonces la privatización de un monopolio bancario a fin de constituir un duopolio con relaciones líder-seguidor es justificable según los siguientes criterios: (i) eficiencia, (ii) poder de mercado/estabilidad financiera y (iii) disponibilidad de consumo.

Finalizamos esta sección indicando que el análisis corrobora que la privatización bancaria es justificable solo de manera condicionada. Si la privatización conlleva a la formación de un oligopolio en donde se permiten estrategias de tipo Stackelberg, es necesario que se satisfagan ciertas condiciones para que la misma sea justificable. Aquí es importante indicar que las condiciones e indicadores de desempeño bancarios son cuantitativamente diferentes a los estimados en la sección anterior. Este hecho fundamenta los análisis que se realizarán en la siguiente sección.

\section{El Análisis Microeconómico de los Modelos de Privatización BANCARIA}

En esta sección mostramos la estática comparativa y el análisis comparativo de los modelos de privatización. El análisis de estática comparativa nos permitirá estimar los efectos de variaciones en los parámetros sobre las decisiones óptimas y los equilibrios bancarios. El análisis comparativo nos permitirá analizar los efectos de las diferentes estrategias competitivas sobre los sistemas bancarios. La importancia de ambos análisis radica en que los mismos nos permitirán estudiar las privatizaciones y regulaciones bancarias desde una perspectiva microeconómica formal. 
La estática comparativa nos muestra que los efectos de variaciones en los parámetros son cualitativamente similares en ambos modelos de privatización bancaria (véanse Apéndices B y C). Incrementos en los retornos de los préstamos o en la proporción de depositantes maduros aumentan el total de depósitos y ganancias bancarias, el retorno de los depósitos, el consumo de los depositantes maduros y los ingresos del gobierno por privatizar los bancos. Asimismo, incrementos en los parámetros de la oferta reducen los depósitos, las ganancias bancarias y los ingresos del gobierno.

El análisis también muestra que la proporción de activos bancarios, usada con el fin de determinar los ingresos del gobierno por privatizar los bancos, tiene efectos directos en el sistema bancario. Al igual que antes, la estática comparativa muestra que variaciones en esta proporción tienen efectos similares en ambos modelos de privatización. Así incrementos en estas proporciones reducen los depósitos y ganancias, el retorno de los depósitos de largo plazo y el consumo de los depositantes maduros. Lo único que aumenta son los ingresos del gobierno.

El análisis comparativo permite analizar los efectos de las diferentes estrategias competitivas. Este análisis se desarrolla con base en los criterios económicos expuestos con anterioridad. Así, la preferencia del modelo con estrategias de tipo Stackelberg sobre el de tipo Cournot se justificaría en términos de eficiencia si $\pi\left(D_{S}^{*}\right) \leq \pi\left(D_{C}^{*}\right)$. Esta preferencia se argumentaría en términos de la estabilidad financiera y del poder de mercado si $R\left(D_{S}^{*}\right) \geq R\left(D_{C}^{*}\right)$. Asimismo, se justificaría en términos de la disponibilidad de consumo si $c_{1}^{*}\left(D_{S}^{*}\right) \geq c_{1}^{*}\left(D_{C}^{*}\right)$ y $c_{2}^{*}\left(D_{S}^{*}\right) \geq c_{2}^{*}\left(D_{C}^{*}\right)$.

El análisis comparativo sugiere que, dada la decisión de privatizar los bancos, es preferible permitir estrategias de tipo Stackelberg a aquellas de tipo Cournot. Esta afirmación se sustenta en el cumplimiento de las siguientes desigualdades: $\pi\left(D_{S}^{*}\right)<\pi\left(D_{C}^{*}\right), R\left(D_{S}^{*}\right)>R\left(D_{C}^{*}\right), c_{1}^{*}\left(D_{S}^{*}\right)=c_{1}^{*}\left(D_{C}^{*}\right) \mathrm{y}$ $c_{2}^{*}\left(D_{S}^{*}\right)>c_{2}^{*}\left(D_{C}^{*}\right) \cdot{ }^{27}$ Incluso, el análisis muestra que $D_{S}^{*}>D_{C}^{*}$. En consecuencia, el permitir relaciones líder-seguidor entre los bancos privatizados induce mayores niveles de eficiencia y estabilidad financiera en la banca, así como reducciones en el poder de mercado y mejoras en los servicios a los depositantes.

Los beneficios económicos de privatizar cuando hay estrategias de tipo Stackelberg no se limitan a los bancos y depositantes. El análisis comparativo muestra que los ingresos del gobierno por privatizar son mayores cuando se permiten estrategias competitivas de tipo Stackelberg en el sistema bancario. Esto ocurre porque $G\left(D_{S}^{*}\right)>G\left(D_{C}^{*}\right)$. De hecho, los ingresos gubernamentales adicionales asociados a este tipo de interacción se obtienen sustrayendo la expresión (14) a la (27):

27 Los cálculos que justifican estas desigualdades están en el apéndice D. 


$$
G\left(D_{S}^{*}\right)-G\left(D_{C}^{*}\right)=\frac{1}{12}\left(\frac{P(1-\Theta)\left(r_{L}-a\right)-P^{2}}{b(1-\Theta)}\right)>0
$$

Las desigualdades asociadas al análisis comparativo muestran que la justificación económica de la privatización y el desempeño de la banca privatizada dependen en buena medida de las formas de competencia permitidas en la misma. Podemos sintetizar nuestros resultados en la siguiente proposición:

Resultado 3: Si se cumplen las condiciones suficientes en la banca, $(1-\Theta)\left(r_{L}-a\right)-4 P>0$ y $(1-\Theta)\left(r_{L}-a\right)-3 P>0$, el permitir estrategias competitivas de tipo Stackelberg es preferible a permitir estrategias de tipo Cournot según los siguientes criterios: (i) eficiencia, (ii) poder de mercado/ estabilidad financiera, (iii) disponibilidad de consumo y (iv) ingresos gubernamentales recabados.

Es importante señalar que el Resultado 3 está acotado a las condiciones suficientes usadas en las secciones anteriores. Adviértase que estas condiciones eran matemáticas, no económicas. En consecuencia, resulta válido preguntarse qué tan restrictivas resultan las mismas. Por comodidad, reescribimos estas condiciones suficientes para los modelos de tipo Cournot y Stackelberg. Estas son, respectivamente, las siguientes desigualdades:

$$
\begin{aligned}
& (1-\Theta)\left(r_{L}-a\right)-4 P>0 \\
& (1-\Theta)\left(r_{L}-a\right)-3 P>0
\end{aligned}
$$

El análisis de las condiciones suficientes sugiere que la conveniencia de la privatización depende de los bancos, los depositantes y el gobierno. Esta conveniencia depende de las desigualdades paramétricas (36) y (37). Tales desigualdades se cumplen si hay relativamente altos retornos de los préstamos, altas proporciones de depositantes maduros o bajos costos por privatizar. Teóricamente las desigualdades son interesantes porque corroboran que son necesarias ciertas condiciones estables durante las liberalizaciones financieras a fin de garantizar su éxito (véase Fry, 1997).

La posibilidad de incumplimiento de las condiciones suficientes que justifican la conveniencia económica de la privatización obliga a analizarlas con cierto cuidado. La comparación entre las desigualdades (36) y (37) sugiere que su cumplimiento es menos restrictivo para la segunda desigualdad bajo parámetros iguales. Esto puede verse si se igualan ambas desigualdades a cero y se despejan las $P$. Estas serán las proporciones de precio de venta límite para que las desigualdades se cumplan. Estas proporciones límite, para los modelos de tipo Cournot y Stackelberg, son $P_{C}$ y $P_{S}$ : 


$$
\begin{aligned}
& P_{C}=\frac{(1-\Theta)\left(r_{L}-a\right)}{4} \\
& P_{S}=\frac{(1-\Theta)\left(r_{L}-a\right)}{3}
\end{aligned}
$$

Las proporciones (38) y (39) muestran que una privatización bancaria es más sencilla de justificar si se permiten estrategias competitivas de tipo Stackelberg. Adviértase que las proporciones $P_{C}$ y $P_{S}$ determinan los precios máximos de venta de los bancos. En consecuencia, la privatización es justificable sólo si los precios cobrados por el gobierno son lo suficientemente bajos $\left(P<P_{C}\right.$ o $\left.P<P_{S}\right)$. Sin embargo, dado que $P_{C}<P_{S}$, bien puede ocurrir que $P_{C}<P<P_{S}$. Esto es, puede darse el caso de que la privatización sólo sea justificable si se permitieran relaciones líder-seguidor en el mercado de depósitos.

Así, el análisis sugiere que la conveniencia de privatizar depende de las formas de vender a los bancos (políticas públicas asociadas). Particularmente, nuestros resultados muestran que la privatización es más sencilla de justificar si se permiten relaciones líder-seguidor en la banca privatizada. Estos resultados se sintetizan en la siguiente proposición:

Resultado 4: Si el precio cobrado por el gobierno, $P$, es lo suficientemente bajo, $P<P_{C}<P_{S}$, la privatización de un monopolio bancario es justificable económicamente si se permiten estrategias competitivas de tipo Cournot $o$ Stackelberg en el mercado de depósitos. Si se cumple que $P_{C}<P<P_{S}$, la privatización es justificable, únicamente, cuando se permiten estrategias de tipo Stackelberg.

¿Cuál es la justificación no matemática por la cual es preferible privatizar cuando se permiten estrategias de tipo Stackelberg? Teóricamente esta conclusión se basa en el hecho de que los juegos Stackelberg son dinámicos. ${ }^{28}$ Estos juegos se caracterizan porque en el transcurso de los mismos emerge nueva información para los jugadores. Esta información se traduce en compromisos y menor incertidumbre (relaciones líder-seguidor). Factores que mejoran las decisiones y el desempeño bancarios y facilitan el cumplimiento de las condiciones que justifican la privatización de los bancos.

Así, el argumento a favor de permitir relaciones líder-seguidor en la banca privatizada es informacional. En este contexto, la credibilidad y compromiso de los bancos líderes son sumamente importantes. El desempeño bancario depende de estos atributos. ${ }^{29}$ Estas consideraciones nos validan la creencia referente a que es necesario tomar en cuenta la reputación y experiencia de los potenciales

\footnotetext{
Adviértase que los juegos Cournot son estáticos.
}

29 Esta afirmación se basa en el hecho de que el equilibrio Stackelberg es inestable ante imperfecciones en la capacidad de los jugadores para determinar la conducta de los líderes. Véase Bagwell (1995). 
compradores y administradores de las firmas privatizadas. Por tanto, no sobra enfatizar que el análisis implica que las decisiones de privatización no debieran depender de consideraciones exclusivamente monetarias.

Finalizamos esta sección indicando que los resultados sugieren que es preferible la privatización bancaria cuando se permiten estrategias de tipo Stackelberg en el mercado de depósitos. Particularmente, la privatización es más sencilla de justificar cuando hay relaciones líder-seguidor que cuando hay bancos idénticos. La eficiencia y estabilidad financiera, así como la reducción del poder de mercado y la mejora de los servicios bancarios son mayores cuando se permiten estas relaciones. Incluso, los ingresos gubernamentales por privatizar son mayores cuando se permiten las mismas.

\section{Conclusiones y Discusión}

En esta investigación hemos estudiado las relaciones teóricas entre la privatización, la competencia y el desempeño de los bancos. Específicamente hemos analizado la conveniencia y efectos de privatizar cuando se permiten estrategias competitivas de tipo Cournot y Stackelberg en la banca privatizada. El análisis se basa en el desarrollo de modelos donde se describen sistemas bancarios caracterizados por fallas de mercado y donde es posible que ocurran crisis. Estos modelos se construyen con elementos de las teorías de la microeconomía y privatización bancarias y la liberalización financiera.

Las conclusiones de los modelos microeconómicos sugieren que bajo ciertos criterios la privatización bancaria es justificable. Dichos criterios incluyen consideraciones de eficiencia y estabilidad financiera, así como de reducción de poder de mercado y la mejora de los servicios bancarios (disponibilidad de consumo de los depositantes). Las condiciones incluyen, entre otras, conductas predecibles de los depositantes, prácticas competitivas en el mercado de depósitos y precios de venta de bancos bajos. Así, los efectos de la privatización dependen de los depositantes, los bancos y el gobierno.

El análisis de estática comparativa muestra que variaciones en los parámetros que definen a los modelos Cournot y Stackelberg tienen efectos cualitativamente similares sobre los sistemas bancarios. Así, el análisis muestra cómo incrementos en los retornos de los préstamos, en las proporciones de depositantes maduros o bien reducciones en los precios de venta de los bancos afectan el desempeño de los sistemas bancarios. Los efectos asociados a estos cambios incluyen el aumento de los depósitos y ganancias, así como del retorno de los depósitos de largo plazo y del consumo de los depositantes.

El análisis microeconómico también sugiere que es preferible permitir estrategias competitivas de tipo Stackelberg en la banca privatizada. El análisis comparativo muestra que la privatización es más sencilla de justificar cuando hay relaciones líder-seguidor que cuando hay bancos idénticos (simétricos). Incluso, los resultados también indican que los ingresos gubernamentales por privatizar son mayores cuando se permiten tales relaciones. Ello puede explicarse porque 
las relaciones líder-seguidor son un mecanismo informacional que mejora el desempeño económico en la banca.

Los resultados de esta investigación conllevan implicaciones y sugerencias de política económico-financiera. Una primera se refiere a la necesidad de mantener las estrategias competitivas tras la privatización bancaria. El desempeño bancario y la conveniencia de la privatización dependen de que las estrategias se preserven tras la venta de los bancos. Si las estrategias fueran modificadas, las condiciones que garantizan la conveniencia de la privatización podrían cambiar y, eventualmente, no cumplirse. En este caso, bien podría ocurrir que se fomentaran ineficiencias, bajos retornos para los depositantes, malos servicios bancarios, inestabilidad bancaria y crisis financieras.

Una segunda implicación asociada se refiere a la necesidad de monitorear y supervisar el entorno de la privatización bancaria. La privatización no inicia ni termina con la venta de los bancos. Tampoco es siempre conveniente. Estas consideraciones son importantes porque los parámetros, conductas y variables que justifican la privatización pueden cambiar con el tiempo debido a razones institucionales, económicas y especulativas (choques externos). Por esto, creemos que estos cambios deben ser monitoreados, evaluados $\mathrm{y}$, eventualmente, contrarrestados para evitar problemas en la banca. ${ }^{30}$

Una tercera implicación se refiere a la regulación bancaria y financiera. $L a$ supervisión y regulación bancarias deben centrarse en las fallas microeconómicas. Las autoridades financieras deben poner atención en las externalidades, el poder de mercado y en los problemas de información incompleta y asimétrica. Particularmente, en el contexto de las privatizaciones, creemos que la atención de las autoridades debiera centrarse en los determinantes de la fragilidad sistémica (regulación prudencial). La experiencia histórica muestra que los costos económicos y fiscales de las crisis bancarias son muy grandes.

Una última implicación se refiere a la conveniencia de explicitar las prácticas de regulación bancaria. En los modelos, la regulación define las conductas de los bancos y el desempeño del sistema bancario. Más aún, provee elementos para determinar la conveniencia de la privatización. Esto implica que las prácticas regulatorias competitivas y prudenciales deben ser dadas a conocer con anticipación a la venta de los bancos. ${ }^{31} \mathrm{Si}$ esto no ocurre así, la justificación y

30 Existen factores no económicos que también definen el entorno, conveniencia y efectos de las privatizaciones bancarias. Si bien en este trabajo no los hemos considerado, debemos reconocer que su importancia no debe subestimarse. Véase el estudio de Boehmer, Nash y Netter (2005), para un análisis empírico de los determinantes políticos de las privatizaciones bancarias.

31 En este trabajo las regulaciones competitivas y prudenciales tienden a complementarse y reforzarse mutuamente. Sin embargo, esto pudiera no ser necesariamente el caso si se introdujeran fallas en los mercados de crédito. Tradicionalmente se afirma que la información asimétrica en estos últimos mercados induce dilemas entre la competencia y la estabilidad financiera (Carletti, 2008). Bajo estas circunstancias, las regulaciones competitivas y prudenciales bien pudieran ser diferenciadas y no complementarias. 
efectos de la privatización serán inciertos. La incertidumbre tiende a empeorar el desempeño económico de los bancos privatizados.

Teóricamente, el marco microeconómico propuesto parece bastante útil para analizar las privatizaciones bancarias. Sin embargo, justo es enfatizar que tiene limitaciones. Estas se asocian principalmente a la ausencia de fallas en los mercados de activos bancarios. Estas fallas pudieran reducir la eficiencia, el crédito y los depósitos, así como restringir las condiciones que justificarían a la privatización. Si bien estas consecuencias son predecibles, es difícil hacer predicciones más específicas porque en la teoría económica no existen reglas generales para analizar situaciones subóptimas.

Finalizamos este trabajo enfatizando que la privatización bancaria es un campo fértil para desarrollar investigación. Particularmente, creemos que el marco expuesto aquí podría extenderse en varias direcciones no abordadas aquí. Una extensión inmediata se refiere al análisis de la privatización cuando hay imperfecciones en los mercados de crédito. ${ }^{32}$ Una segunda podría abarcar el estudio de otros justificantes de la privatización. ${ }^{33}$ Una tercera podría abarcar el análisis de la privatización y el bienestar social. ${ }^{34}$ Por ello, creemos que la mayor contribución de este trabajo consiste en proponer un marco formal para analizar políticas y decisiones de privatización bancaria.

\section{REFERENCIAS}

Bagwell, K. (1995). "Commitment and Observability in Games”, Games and Economic Behavior, Vol. 8; 271-280.

Berger, A. N. y Hannan, T. H. (1992). "The Price-Concentration Relationship in Banking: A Reply", The Review of Economics and Statistics, Vol. 74; 376-379.

Berger, A. N. y Hannan, T. H. (1989). “The Price-Concentration Relationship in Banking”, The Review of Economics and Statistics, Vol. 71; 291-299.

32 Esta extensión permitiría examinar las privatizaciones bancarias ocurridas en Chile y México durante los años setenta y noventa. En ambos casos hubo problemas de regulación y supervisión. Estos problemas, aunados a otros de información asimétrica indujeron riesgos crediticios que derivaron en crisis bancarias y rescates gubernamentales. Véanse, entre otros, los estudios de Vergara (1996), Gruben y McComb (2003) y Haber (2005).

33 Existen racionalidades económicas alternativas que explican por qué existen distintas configuraciones institucionales para proporcionar bienes y servicios como los bancarios. Por ejemplo, Stein (1996) indica que la forma en que los gobiernos se organizan para proporcionar servicios es una función del alcance y contenido de los servicios comprometidos por el gobierno para con la sociedad. En consecuencia, para este autor, las decisiones de privatizar o no dependen de consideraciones organizacionales.

34 Es importante señalar que la evaluación del bienestar social en sistemas bancarios públicos y privados podría justificar la conveniencia de privatizaciones desde una perspectiva complementaria a la de esta investigación (véase nota 23). El análisis de la privatización, las fusiones y el bienestar social en oligopolios bancarios mixtos también parece ser una veta promisoria de análisis. Véase a Méndez-Naya (2007), para una investigación similar en el contexto de firmas no financieras. 
Boehmer, E.; Nash, R. C. y Netter, J. M. (2005). "Bank Privatization in Developing and Developed Countries: Cross-Sectional Evidence on the Impact of Economic and Political Factors", Journal of Banking and Finance, Vol. 29; 1981-2013.

Boubakri, N.; Cosset, J.C.; Fischer, K. y Guedhami, O. (2005). "Privatization and Bank Performance in Developing Countries", Journal of Banking and Finance, Vol. 29; 2015-2041.

Calem, P. S. y Carlino, G. A. (1991). "The Concentration/Conduct Relationship in Bank Deposit Markets", The Review of Economics and Statistics, Vol. 73; 268-276.

Caprio, G.; Fiechter, J.; Litan, R. E. y Pomerleano, M. (Editores). (2005). The Future of State-Owned Financial Institutions, Brookings Institution Press.

Carletti, E. (2008). "Competition and Regulation in Banking”, en Boot y Thakor (editores), Handbook of Financial Intermediation and Banking, North Holland.

Clarke, G. R. G.; Cull, R. y Shirley, M. (2005). "Bank Privatization in Developing Countries: A Summary of Lessons and Findings", Journal of Banking and Finance, Vol. 29; 1905-1930.

Demirguc-Kunt, A. y Detragiache, E. (1998). "Financial Liberalisation and Financial Fragility", Policy Research Working Paper 1917, World Bank.

Diamond, D. W. y Dybvig, P. H. (1983). "Bank Runs, Deposit Insurance, and Liquidity", Journal of Political Economy, Vol. 91; 401-419.

Diaz-Alejandro, C. (1985). "Good-Bye Financial Repression, Hello Financial Crash", Journal of Development Economics, Vol. 19; 1-24.

Dowd, K. (1996). "The Case for Financial Laissez-Faire”, Economic Journal, Vol. 106; 679-687.

Freixas, X. y Rochet, J.C. (2008). Microeconomics of Banking, Segunda edición, The MIT Press.

Fry, M. J. (1995). Money, Interest, and Banking in Economic Development, Segunda edición, The Johns Hopkins University Press.

Fry, M. J. (1997). "In Favour of Financial Liberalisation", Economic Journal, Vol. 107; 754-770.

Gruben, W. C. y R. P. McComb. (2003). "Privatization, Competition, and Supercompetition in the Mexican Commercial Banking System", Journal of Banking and Finance, Vol. 27; 229-249.

Haber, S. (2005). "Mexico's Experiments with Bank Privatization and Liberalization, 1991-2003”, Journal of Banking and Finance, Vol. 29; 2325-2353.

Heffernan, S. (2005). Modern Banking, John Wiley \& Sons.

Hutchison, D. E. (1995). "Retail Bank Deposit Pricing: An Intertemporal Asset Pricing Approach", Journal of Money, Credit and Banking, Vol. 27; 217-231.

McKinnon, R. I. (1993). The Order of Economic Liberalization: Financial Control in the Transition to a Market Economy, Segunda edición, The Johns Hopkins University Press.

McKinnon, R. I. (1973). Money and Capital in Economic Development, Brookings Institutions.

Megginson, W. L. (2005a). "The Economics of Bank Privatization”, Journal of Banking and Finance, Vol. 29; 1931-1980. 
Megginson, W. L. (2005b). The Financial Economics of Privatization, Oxford University Press.

Méndez-Naya, J. (2007). "Privatización y Fusiones en Oligopolios Mixtos", Estudios de Economía, Vol. 34; 37-52.

Ortiz-Martínez, G. (1994), La Reforma Financiera y la Desincorporación Bancaria, Fondo de Cultura Económica.

Otchere, I. (2005). "Do Privatized Banks in Middle-and Low-Income Countries Perform Better than Rival Banks? An Intra-Industry Analysis of Bank Privatization", Journal of Banking and Finance, Vol. 29; 2067-2093.

Revilla, J. (1996). "Un modelo Stackelberg del Mercado Bancario en Nicaragua: El Caso de la Banca Estatal y su Impacto en la Determinación de la Tasa de Interés", Documento de Trabajo 1-1996, Banco Central de Nicaragua.

Saha, B. y Sensarma, R. (2004). "Divestment and Bank Competition", Journal of Economics, Vol. 81; 223-247.

Shaw, E. (1973). Financial Deepening in Economic Development, Oxford University Press.

Sheshinski, E. y López-Calva, L. F. (2003). "Privatization and its Benefits: Theory and Evidence", CESifo Economic Studies, Vol. 49; 429-459.

Stein, R. M. (1996). "Privatization and the Arrangement of City Services", Estudios de Economía, Vol. 23; 1-23.

Stiglitz, J. E. (1994). "The Role of the State in Financial Markets", en Bruno y Pleskovic (editores), Proceedings of the World Bank Annual Bank Conference on Development Economics 1993, World Bank.

Vérgara, R. (1996). "Privatización de la Banca: La Experiencia Chilena", Estudios Públicos, Vol. 63; 335-345.

Wu, H.L. y Parker, D. (2007). "The Determinants of Post-Privatization Efficiency Gains: The Taiwanese Experience", Economic and Industrial Democracy, Vol. 28; 465-493.

Zhou, X.; Chang, K.P.; Hou, X. y Ji, S. (2009). "Endogenous Timing and Banking Competition in a Mixed Oligopoly: A Theoretical Perspective on the Banking Industry in China", Working Paper 1418515, Social Science Research Network. 


\section{APÉNDICES}

\section{A. Estática COMPARATIVA EN EL MONOPOLIO BANCARIO GUBERNAMENTAL}

En este apéndice incluimos las derivadas que muestran los efectos cuantitativos y cualitativos de variaciones en los parámetros en las decisiones óptimas y los indicadores de desempeño asociados al monopolio bancario de propiedad gubernamental.

\section{A.1. Cantidad total de depósitos}

$$
\begin{gathered}
\frac{\partial}{\partial r_{L}} D_{M}^{*}=\frac{1}{2 b}>0 \\
\frac{\partial}{\partial a} D_{M}^{*}=-\frac{1}{2 b}<0 \\
\frac{\partial}{\partial b} D_{M}^{*}=-\frac{r_{L}-a}{2 b^{2}}<0
\end{gathered}
$$

El total de depósitos aumenta cuando se incrementa el retorno de los préstamos o cuando disminuyen los parámetros de la oferta de depósitos.

\section{A.2. Retorno de los depósitos de largo plazo}

$$
\begin{gathered}
\frac{\partial}{\partial r_{L}} R\left(D_{M}^{*}\right)=\frac{1}{2}>0 \\
\frac{\partial}{\partial a} R\left(D_{M}^{*}\right)=\frac{1}{2}>0
\end{gathered}
$$

El retorno pagado a los depositantes de largo plazo aumenta cuando se incrementa el retorno de los préstamos o el parámetro constante de la oferta.

\section{A.3. Ganancias óptimas en el sistema bancario}

$$
\frac{\partial}{\partial r_{L}} \pi\left(D_{M}^{*}\right)=\frac{(1-\Theta)\left(r_{L}-a\right)}{2 b}>0
$$




$$
\begin{gathered}
\frac{\partial}{\partial a} \pi\left(D_{M}^{*}\right)=-\frac{(1-\Theta)\left(r_{L}-a\right)}{2 b}<0 \\
\frac{\partial}{\partial b} \pi\left(D_{M}^{*}\right)=-(1-\Theta)\left(\frac{r_{L}-a}{2 b}\right)^{2}<0 \\
\frac{\partial}{\partial \Theta} \pi\left(D_{M}^{*}\right)=-\frac{\left(r_{L}-a\right)^{2}}{4 b}<0
\end{gathered}
$$

Las ganancias en el sistema bancario aumentan cuando se incrementan el retorno de los préstamos o la proporción de depositantes maduros. Además, las ganancias aumentan cuando disminuyen los parámetros de la oferta de depósitos.

\section{A.4. Consumo óptimo de los depositantes}

$$
\begin{gathered}
\frac{\partial}{\partial r_{L}} c_{2}^{*}\left(D_{M}^{*}\right)=\frac{1}{2}>0 \\
\frac{\partial}{\partial a} c_{2}^{*}\left(D_{M}^{*}\right)=\frac{1}{2}>0 \\
\frac{\partial}{\partial \Theta} c_{2}^{*}\left(D_{M}^{*}\right)=0
\end{gathered}
$$

El consumo de los depositantes maduros aumenta cuando se incrementa el parámetro constante de la oferta o el retorno de los préstamos bancarios.

\section{B. ESTÁTICA COMPARATIVA EN EL OLIGOPOLIO CON ESTRATEGIAS de TIPo Cournot}

En este apéndice incluimos las derivadas que muestran los efectos cuantitativos y cualitativos de variaciones en los parámetros en las decisiones óptimas y los indicadores de desempeño asociados al modelo bancario con estrategias de tipo de tipo Cournot. 


\section{B.1. Cantidad total de depósitos}

$$
\begin{gathered}
\frac{\partial}{\partial r_{L}} D_{C}^{*}=\frac{2}{3 b}>0 \\
\frac{\partial}{\partial a} D_{C}^{*}=-\frac{2}{3 b}<0 \\
\frac{\partial}{\partial b} D_{C}^{*}=-\frac{2}{3}\left(\frac{(1-\Theta)\left(r_{L}-a\right)-P}{b^{2}(1-\Theta)}\right)<0 \\
\frac{\partial}{\partial \Theta} D_{C}^{*}=-\frac{2}{3}\left(\frac{P}{b(1-\Theta)^{2}}\right)<0 \\
\frac{\partial}{\partial P} D_{C}^{*}=-\frac{2}{3}\left(\frac{1}{b(1-\Theta)}\right)<0
\end{gathered}
$$

El total de depósitos aumenta cuando se incrementa el retorno de los préstamos o cuando disminuyen los parámetros de la oferta de depósitos. Asimismo, los depósitos disminuyen cuando se incrementan la proporción de depositantes tempraneros o el costo por privatizar a los bancos.

\section{B.2. Retorno de los depósitos de largo plazo}

$$
\begin{gathered}
\frac{\partial}{\partial r_{L}} R\left(D_{C}^{*}\right)=\frac{2}{3}>0 \\
\frac{\partial}{\partial a} R\left(D_{C}^{*}\right)=-\frac{1}{3}<0 \\
\frac{\partial}{\partial b} R\left(D_{C}^{*}\right)=0 \\
\frac{\partial}{\partial \Theta} R\left(D_{C}^{*}\right)=-\frac{2}{3}\left(\frac{P}{(1-\Theta)^{2}}\right)<0
\end{gathered}
$$




$$
\frac{\partial}{\partial P} R\left(D_{C}^{*}\right)=-\frac{2}{3}\left(\frac{1}{(1-\Theta)}\right)<0
$$

El retorno pagado a los depositantes de largo plazo aumenta cuando se incrementa el retorno de los préstamos o cuando disminuye el parámetro constante de la oferta de depósitos. Asimismo, el retorno disminuye cuando se incrementan la proporción de depositantes tempraneros o el costo por privatizar a los bancos.

\section{B.3. Ganancias óptimas en el sistema bancario}

$$
\begin{gathered}
\frac{\partial}{\partial r_{L}} \pi\left(D_{C}^{*}\right)=\frac{4}{9}\left(\frac{(1-\Theta)\left(r_{L}-a\right)-P}{b}\right)>0 \\
\frac{\partial}{\partial a} \pi\left(D_{C}^{*}\right)=-\frac{4}{9}\left(\frac{(1-\Theta)\left(r_{L}-a\right)-P}{b}\right)<0 \\
\frac{\partial}{\partial b} \pi\left(D_{C}^{*}\right)=-\frac{2}{9}\left(\frac{\left((1-\Theta)\left(r_{L}-a\right)-P\right)^{2}}{b^{2}(1-\Theta)}\right)<0 \\
\frac{\partial}{\partial \Theta} \pi\left(D_{C}^{*}\right)=-\frac{2}{9}\left(\frac{\left((1-\Theta)\left(r_{L}-a\right)\right)^{2}-P^{2}}{b(1-\Theta)^{2}}\right)<0 \\
\frac{\partial}{\partial P} \pi\left(D_{C}^{*}\right)=-\frac{4}{9}\left(\frac{(1-\Theta)\left(r_{L}-a\right)-P}{b(1-\Theta)}\right)<0
\end{gathered}
$$

Las ganancias en el sistema bancario aumentan cuando se incrementa el retorno de los préstamos o cuando disminuyen los parámetros de la oferta de depósitos. Asimismo, las ganancias disminuyen cuando se incrementa la proporción de depositantes tempraneros o el costo por privatizar a los bancos.

\section{B.4. Consumo óptimo de los depositantes}

$$
\frac{\partial}{\partial r_{L}} c_{2}^{*}\left(D_{C}^{*}\right)=\frac{2}{3}>0
$$




$$
\begin{gathered}
\frac{\partial}{\partial a} c_{2}^{*}\left(D_{C}^{*}\right)=\frac{1}{3}>0 \\
\frac{\partial}{\partial b} c_{2}^{*}\left(D_{C}^{*}\right)=0 \\
\frac{\partial}{\partial \Theta} c_{2}^{*}\left(D_{C}^{*}\right)=-\frac{2}{3}\left(\frac{P}{(1-\Theta)^{2}}\right)<0 \\
\frac{\partial}{\partial P} c_{2}^{*}\left(D_{C}^{*}\right)=-\frac{2}{3}\left(\frac{1}{1-\Theta}\right)<0
\end{gathered}
$$

El consumo de los depositantes maduros aumenta cuando se incrementan el retorno de los préstamos o el parámetro constante de la oferta de depósitos. Asimismo, el consumo disminuye cuando se incrementan la proporción de depositantes tempraneros o el costo por privatizar a los bancos.

\section{B.5. Ingresos del gobierno por privatizar}

$$
\begin{gathered}
\frac{\partial}{\partial r_{L}} G\left(D_{C}^{*}\right)=\frac{2}{3}\left(\frac{P}{b}\right)>0 \\
\frac{\partial}{\partial a} G\left(D_{C}^{*}\right)=-\frac{2}{3}\left(\frac{P}{b}\right)<0 \\
\frac{\partial}{\partial b} G\left(D_{C}^{*}\right)=-\frac{2}{3}\left(\frac{P(1-\Theta)\left(r_{L}-a\right)-P^{2}}{b^{2}(1-\Theta)}\right)<0 \\
\frac{\partial}{\partial \Theta} G\left(D_{C}^{*}\right)=-\frac{2}{3}\left(\frac{P^{2}}{b(1-\Theta)^{2}}\right)<0 \\
\frac{\partial}{\partial P} G\left(D_{C}^{*}\right)=\frac{2}{3}\left(\frac{(1-\Theta)\left(r_{L}-a\right)-2 P}{b(1-\Theta)}\right)>0
\end{gathered}
$$

Los ingresos totales del gobierno por privatizar los bancos aumentan cuando se incrementa el retorno de los préstamos o cuando disminuyen los parámetros 
de la oferta de depósitos. Asimismo, los ingresos gubernamentales aumentan cuando se incrementa la proporción de depositantes maduros o el costo por privatizar a los bancos.

\section{ESTÁTICA COMPARATIVA EN EL OLIGOPOLIO CON ESTRATEGIAS DE TIPO STACKELBERG}

En este apéndice incluimos las derivadas que muestran los efectos de variaciones en los parámetros en las decisiones óptimas y los indicadores de desempeño asociados al modelo bancario con estrategias competitivas de tipo Stackelberg. Estos efectos son cualitativamente similares a los registrados en el modelo con estrategias de tipo Cournot.

\section{C.1. Cantidad total de depósitos}

$$
\begin{gathered}
\frac{\partial}{\partial r_{L}} D_{S}^{*}=\frac{3}{4 b}>0 \\
\frac{\partial}{\partial a} D_{S}^{*}=-\frac{3}{4 b}<0 \\
\frac{\partial}{\partial b} D_{S}^{*}=-\frac{3}{4}\left(\frac{(1-\Theta)\left(r_{L}-a\right)-P}{b^{2}(1-\Theta)}\right)<0 \\
\frac{\partial}{\partial \Theta} D_{S}^{*}=-\frac{3}{4}\left(\frac{P}{b(1-\Theta)^{2}}\right)<0 \\
\frac{\partial}{\partial P} D_{S}^{*}=-\frac{3}{4}\left(\frac{1}{b(1-\Theta)}\right)<0
\end{gathered}
$$

C.2 Retorno de los depósitos de largo plazo

$$
\frac{\partial}{\partial r_{L}} R\left(D_{S}^{*}\right)=\frac{3}{4}>0
$$




$$
\begin{gathered}
\frac{\partial}{\partial a} R\left(D_{S}^{*}\right)=-\frac{1}{4}<0 \\
\frac{\partial}{\partial b} R\left(D_{S}^{*}\right)=0 \\
\frac{\partial}{\partial \Theta} R\left(D_{S}^{*}\right)=-\frac{3}{4}\left(\frac{P}{(1-\Theta)^{2}}\right)<0 \\
\frac{\partial}{\partial P} R\left(D_{S}^{*}\right)=-\frac{3}{4}\left(\frac{1}{(1-\Theta)}\right)<0
\end{gathered}
$$

\section{C.3. Ganancias óptimas en el sistema bancario}

$$
\begin{gathered}
\frac{\partial}{\partial r_{L}} \pi\left(D_{S}^{*}\right)=\frac{3}{8}\left(\frac{(1-\Theta)\left(r_{L}-a\right)-P}{b}\right)>0 \\
\frac{\partial}{\partial a} \pi\left(D_{S}^{*}\right)=-\frac{3}{8}\left(\frac{(1-\Theta)\left(r_{L}-a\right)-P}{b}\right)<0 \\
\frac{\partial}{\partial b} \pi\left(D_{S}^{*}\right)=-\frac{3}{16}\left(\frac{\left((1-\Theta)\left(r_{L}-a\right)-P\right)^{2}}{b^{2}(1-\Theta)}\right)<0 \\
\frac{\partial}{\partial \Theta} \pi\left(D_{S}^{*}\right)=-\frac{3}{16}\left(\frac{\left((1-\Theta)\left(r_{L}-a\right)\right)^{2}-P^{2}}{b(1-\Theta)^{2}}\right)<0 \\
\frac{\partial}{\partial P} \pi\left(D_{S}^{*}\right)=-\frac{3}{8}\left(\frac{(1-\Theta)\left(r_{L}-a\right)-P}{b(1-\Theta)}\right)<0
\end{gathered}
$$




\section{C.4. Consumo óptimo de los depositantes}

$$
\begin{gathered}
\frac{\partial}{\partial r_{L}} c_{2}^{*}\left(D_{S}^{*}\right)=\frac{3}{4}>0 \\
\frac{\partial}{\partial a} c_{2}^{*}\left(D_{S}^{*}\right)=\frac{1}{4}>0 \\
\frac{\partial}{\partial b} c_{2}^{*}\left(D_{S}^{*}\right)=0 \\
\frac{\partial}{\partial \Theta} c_{2}^{*}\left(D_{S}^{*}\right)=-\frac{3}{4}\left(\frac{P}{(1-\Theta)^{2}}\right)<0 \\
\frac{\partial}{\partial P} c_{2}^{*}\left(D_{S}^{*}\right)=-\frac{3}{4}\left(\frac{1}{1-\Theta}\right)<0
\end{gathered}
$$

\section{C.5. Ingresos del gobierno por privatizar}

$$
\begin{gathered}
\frac{\partial}{\partial r_{L}} G\left(D_{S}^{*}\right)=\frac{3}{4}\left(\frac{P}{b}\right)>0 \\
\frac{\partial}{\partial a} G\left(D_{S}^{*}\right)=-\frac{3}{4}\left(\frac{P}{b}\right)<0 \\
\frac{\partial}{\partial b} G\left(D_{S}^{*}\right)=-\frac{3}{4}\left(\frac{P(1-\Theta)\left(r_{L}-a\right)-P^{2}}{b^{2}(1-\Theta)}\right)<0 \\
\frac{\partial}{\partial \Theta} G\left(D_{S}^{*}\right)=-\frac{3}{4}\left(\frac{P^{2}}{b(1-\Theta)^{2}}\right)<0 \\
\frac{\partial}{\partial P} G\left(D_{S}^{*}\right)=\frac{3}{4}\left(\frac{(1-\Theta)\left(r_{L}-a\right)-2 P}{b(1-\Theta)}\right)>0
\end{gathered}
$$




\section{ANÁlisis COMPARATIVo de LOS MODELOS DE PRIVATIZACIÓN BANCARIA}

En este apéndice se comparan los indicadores de desempeño bancarios asociados a los modelos de tipo Stackelberg y Cournot. Esta comparación se basa en la estimación de las diferencias de los indicadores asociados a los criterios de eficiencia, estabilidad financiera, poder de mercado y disponibilidad de consumo. Asimismo, incluimos la interpretación correspondiente.

$$
\begin{gathered}
D_{S}^{*}-D_{C}^{*}=\frac{1}{12}\left(\frac{(1-\Theta)\left(r_{L}-a\right)-P}{b(1-\Theta)}\right)>0 \\
R\left(D_{S}^{*}\right)-R\left(D_{C}^{*}\right)=\frac{1}{12}\left(\frac{(1-\Theta)\left(r_{L}-a\right)-P}{(1-\Theta)}\right)>0 \\
\pi\left(D_{S}^{*}\right)-\pi\left(D_{C}^{*}\right)=-\frac{5}{144}\left(\frac{\left((1-\Theta)\left(r_{L}-a\right)-P\right)^{2}}{b(1-\Theta)}\right)<0 \\
c_{1}^{*}\left(D_{S}^{*}\right)-c_{1}^{*}\left(D_{C}^{*}\right)=0 \\
c_{2}^{*}\left(D_{S}^{*}\right)-c_{2}^{*}\left(D_{C}^{*}\right)=\frac{1}{12}\left(\frac{(1-\Theta)\left(r_{L}-a\right)-P}{(1-\Theta)}\right)>0
\end{gathered}
$$

La comparación entre modelos muestra que el total de depósitos en el sistema bancario, el retorno pagado a los depositantes de largo plazo y el consumo de los depositantes maduros son mayores cuando hay estrategias de tipo Stackelberg que cuando hay estrategias de tipo Cournot. Esto no ocurre con el total de ganancias bancarias. En este último caso, las mismas son menores cuando hay estrategias de tipo Stackelberg. El consumo de los depositantes tempraneros es similar en ambas estrategias. 